\title{
Timor and historical research
}

Timor is situated to the northwest of [Zhong-] Jia Luo. Its mountains do not grow any other trees but sandalwood that is most abundant. It is traded for silver, iron, cups [of porcelain], cloth from Western countries and coloured taffetas. There are altogether twelve localities which are called ports. There is a local chieftain. The soil is suitable for the raising of grain. The climate is irregular, hot in the day, cool at night. The habits of the natives are obscene. Men and women cut their hair and wear short cotton skirts. They tie them around with cloth from Champa. Market prices of spirits and meats are reasonable. The women are shameless. The tribal chiefs are fond of food, wine and sex, and when sleeping they do not cover themselves so that those who get infected [by diseases] die for the most part. If one has been careless while among the natives, the disease will break out with attacks of high fever once the ship has returned to China. ${ }^{1}$

This is how a Chinese geographer presented the distant Southeast Asian island circa 1350, and it is one of the earliest known descriptions. About 450 years later, in 1801, the French explorer Péron ${ }^{2}$ described the same land in somewhat more elaborate language: ${ }^{3}$

Barely two days had passed since we left the dry coasts of New Holland, and we could already behold the lofty mountains of Timor. Three sets of haughty rocks, running parallel to the length of the island, con-

\footnotetext{
$1 \quad$ Dao yi Zhi lue (circa1350), quoted in Ptak 1983:37.

2 Not to be confused with Jean-Baptiste Pelon, a Frenchman in Dutch service who wrote a valuable study of Timor in 1778, Description de Timor occidental et des îles sous domination hollandaise (1771-1778); see Pelon 2002.

3 Please note that all translations of non-English sources are mine, unless otherwise indicated.
} 
stituted a threefold amphitheatre, whose furthest lying tiers, set back into the ground, also seemed to be the highest. The shape of these mountains, although lofty, was somehow mellow; their regular and uniform extensions and their steep summits were imperceptibly softened by the gentle waves, which died down by the seashore. The mountain slopes were completely covered with mighty vegetation; the outlines of all the valleys were marked by the green foliage of dense forests, above which the elegant tops of coconut palms, areca trees and borassus palms rose on all sides - the happy product of the equatorial climates.

Soon we had passed the coasts of Amarasi; we found ourselves at the mouth of the strait that, together with Timor, makes up the island of Rote, more famous for its beautiful women than for its copper mines. On the morning of 21 August we crossed this strait; after having passed the northern point of the small island of Landu, which, like many other islands, is often confused with Rote on the standard maps, we discovered the entrance of a second strait, formed by the island of Semau, which curves towards the western point of Timor. At two o'clock we cast anchor in the middle of this strait, opposite a pretty bay belonging to the island of Semau. It would perhaps be hard to find anywhere else more charming and picturesque than the place which we currently enjoyed; surrounded by the land on all sides, it was as if we were in the midst of a beautiful lake; fishes of all kinds, adorned with the richest colours, lived in these calm waters and multiplied in its depths; and wherever we turned our eyes, this image of pure fertility seemed to repeat itself with even more charm and interest. What a contrast to the nearby north-western coastlines of New Holland, so monotonous and sterile! ${ }^{4}$

The same island was therefore commented upon by short-term visitors who travelled from afar. While it is likely that the geographical features of Timor were comparable in 1350 and 1800, it is remarkable that the tone of both descriptions differs considerably. For the Chinese, Timor was an island of some importance because of its resources of white sandalwood (santalum album), the fragrant qualities of which made it suitable for making incense and artwork. However, the doubtful standards of its inhabitants, the intolerable heat and the unhealthy living conditions

4 Péron, 1807:141-2. Landu is in fact no island, but is part of Rote. In most of the quotations in this work I have rendered geographical and personal names in their modern form, in instances when there is no ambiguity about it. 
made it a place to avoid if possible. For the explorer Péron on the other hand, who had no business to attend to there, Timor was a highly captivating place. Though the Frenchman soon became aware of the island's darker side, its beauty and interesting ethnographic composition added a flavour of good-natured curiosity to his account.

Ever since the days of the medieval Chinese merchants, the image of Timor has oscillated between these two extremes. This Southeast Asian island, roughly equivalent to the Netherlands in size, has been visited over the centuries by Portuguese, Dutch and British travellers among others, and is often described in rather strong categorical terms. Indeed, the viewpoints differ to the degree that one cannot help but wonder if they are talking about the same island. If the inhabitants are valiant and warlike in one text, they are weak and cowardly in the other; if they are nimble and dexterous in one account, they are lazy and primitive in the other; if the Timorese women are considered to be of high standing in one narrative, they are badly oppressed to the point of enslavement in the other.

The problem in grasping the fundamentals of Timorese society in a historical setting is obvious: the island is comparatively large, but lies far away from the western and central parts of the Southeast Asian Archipelago, which constitute a meeting point of cultures. From a historical perspective, the cluster of islands to the east of Sumbawa tends to be settled by small polities and ritual communities with a comparatively low level of (conventional) technological sophistication. In these societies clan, house, marriage patterns and ancestors become crucial nodes in what the anthropologist Jim Fox has called 'the flow of life'. While islands such as Flores, Sumba, Timor and Solor have generated a substantial amount of interest from anthropologists, the same cannot be said of historians, something which is partly due to the nature of the sources. It is not entirely true that the art of writing was unknown among the Timorese until recently, but there is only a limited amount of pre-1900 texts written or dictated by indigenous people. The great bulk of the source material from the long era of colonial presence - from the seventeenth to the twentieth century - was produced by officials and visitors of European extraction. One might say that the history of Timor is doomed to be studied through Western eyes.

\footnotetext{
5 For a popular introduction to this notion, see Fox 1991b; for an extended survey, see Munandjar Widiyatmika 2008.
} 
In spite of this, the present work attempts to trace the indigenous political and social structures in Timor during an era that, for reasons soon to be explained, may be termed 'early colonial', thus encompassing the age of the Vereenigde Oost-Indische Compagnie (VOC, Dutch East India Company, hereafter also rendered as 'the Company') in the seventeenth and eighteenth centuries. The main question addressed by this study relates to the methods of interaction between colonial and indigenous organizations, and the changes in local society brought about as a consequence of this interaction. In other words, the book will scrutinize how forms of material culture, religion, ideology, political domination and trade were adapted for or imposed on the island by external individuals, and how the indigenous populations strove to adapt or resist these influences. In order to see the Timorese development within a geographical context, I also discuss the role of surrounding islands, in particular Solor and easternmost Flores, both of which were colonial stepping stones to Timor. Postcolonial studies in their broader sense tend to focus on forms of culture influenced by the imperial process since the inception of colonialism, and several issues raised by this line of study can be applied to the early colonial context of Timor. Thus, while not denying the asymmetric and often oppressive features of the colonial relationship, one should avoid seeing it as a simplistic one-sided process. Rather, it is essential to identify the constituent roles of colonizer and colonized, and to trace their hybrid forms, that is, an insoluble intermingling, via interaction, of the (colonizing) centre and the (colonized) periphery. ${ }^{6}$

The case of Timor is of particular interest within the context of Southeast Asia. In spite of having been visited by foreign traders for many hundreds of years, the island is not very accessible, and regular visits need to be well planned and to fit around the monsoon pattern. The oft-repeated but untrue rumour that Timor was covered by sandalwood forests drew European traders to its shores from an early stage: the first documented visit, by the remains of the Magellan expedition, took place in 1522, and Portuguese traders visited the island from at least 1523 (Le Roux 1929; Newitt 2005:122). Regular Portuguese and Dutch establishments on the Timorese coast date from the mid-seventeenth century, and

$6 \quad$ Nünning 2005:68, 181-2. I will make no attempt here to define the ambiguous field of postcolonial studies; for an overview of this, see Gandhi 1998; Slater 1998. 
from circa 1670 most princedoms ${ }^{7}$ on the island were subjected to an amount of European (or Eurasian) political precedence. In spite of these early beginnings, thorough colonial rule as understood in conventional terms was hardly implemented before the late nineteenth and early twentieth century. ${ }^{8}$ Self-critical Dutch and Portuguese writers readily acknowledged the limited means that the colonial establishments had at their disposal to enforce their will on the innumerable local princedoms; 'colonial' rule was indeed often little more than window dressing (Castro 1862; Kniphorst 1885).

'Indirect rule' might be a better term, though it would be more judicious to speak of an indirect implementation of a political and economic network. The small Dutch and Portuguese detachments stayed in coastal settlements from which they tried to manage the trade and deliveries of sandalwood, beeswax and slaves - their main raison d'être - with the little manpower available.

Clearly, this situation is not unique to Timor. Rather, indirect rule was the most common way of handling European trading capitalism in the coastlands of Asia up until the nineteenth century. 'Early colonial' is therefore a term that is best used for this period of Western impact on the area. ${ }^{9}$ Nevertheless, the difficulties faced by the colonial organizations in getting to grips with the indigenous people over the course of two or three centuries raises questions about the ability of a comparatively low-technological local society to resist highly-technological external intruders. Explanations of the maintenance of such resistance may be sought in cultural features, societal organization, ways of warfare and, not least, in geographical factors. On the other hand, the very fact that there was a degree of Timorese attachment to the Dutch East India Company and the Portuguese king suggests that arenas of interaction and exchange developed, whereby political authority was not simply a matter of enforcement. One may refer here to the 'stranger king' syndrome, which has been popular with scholars of Southeast Asian history

\footnotetext{
7 In this work, I use the terms 'princedom' or 'domain' rather than 'kingdom' for political units. The non-bureaucratized and indeed non-centralized nature of these units means that the term 'kingdom' would misdirect the reader. At the same time, I retain the European term 'king' (koning, rei) for the heads of local polities rather than the somewhat non-descriptive 'ruler', 'chief' or 'prince'. All this will be discussed further in Chapter III.

8 See in particular the detailed studies of Davidson 1994; Farram 2003; Schlicher 1996.

9 That is, in the first place for Asia and Africa. The more intense colonization of parts of the Americas after 1492, with massive resettlement and extermination of peoples, differs greatly from the outlined pattern.
} 
in recent years. ${ }^{10}$ Societies with a stateless or non-bureaucratic structure have often tended to refer to a ruler or a dynasty as an outsider, who purportedly comes from another geographical location, often associated with the sea. The stranger king is ideally accepted by a particular polity as a commanding force, whose foreignness puts him in a position to mediate and keep the various competitive elements of the polity in check. Various examples from the Southeast Asian Archipelago indicate that common ethnicity and matrimonial arrangements were far from sufficient to build a politically integrated society. Small-scale societies often maintained an economy of gift exchange, which may have been more significant in the construction of political networks. However, the competitive nature of such exchanges also easily made for conflicts; a stranger who had few emotional bonds with the indigenous groups would be ideally placed to act as a facilitator of conflict resolution. As will be seen, this syndrome is highly relevant to the Timorese case, where the Dutch East India Company was literally seen as a 'prince' (usi); the surrounding discussion can be elaborated on by drawing on the results of modern anthropological research. ${ }^{11}$ The European outsider was, to such an extent, placed inside, localized within a system that made him indispensable and surrounded him with symbols and rites of precedence. In fact, the Dutch post in Kupang, West Timor, was surrounded by allied princedoms who stayed loyal to the foreign lords from the 1650 s until the twentieth century, in spite of periods of obvious misrule. As the allies put it to a white tuan (gentleman) in the face of a British invasion attempt in 1797: 'We rajas have the land and tuan has the sea.'12 The lords of the land paid their deference to the lord of the sea whilst still having the means to wield power during negotiations.

Another interesting point is the presence, for some three centuries, of two colonial organizations who were within the vicinity of each other. Such an existence of two centres of colonial authority, which, for most of the time, had a mutually hostile attitude, is rather unique in a Southeast

\footnotetext{
1o The discussion about the 'stranger king' syndrome in this book owes much to Henley (2002), who studied a case from northern Sulawesi, both similar yet quite dissimilar in parts. For more on the stranger king, see Sahlins 1981; Fox 2008; Barnes 2008.

${ }_{11}$ Middelkoop 1952:227. Traube 1986:52-4 contains a discussion of a related theme with regard to the East Timorese views of the Portuguese.

12 LOr 2242, UB Leiden. The VOC was not normally addressed as 'Lord of the Sea', but there might be an idea of an opposition between the 'female' land and 'male' sea here, in accordance with Timorese traditional concepts. 'Stranger kings' in Southeast Asia tended to be associated with the sea.
} 
Asian context. Although a formal lasting peace between the Netherlands and Portugal was announced in Europe in 1663, the history of their Timorese possessions is one of suspicion, intrigue and wars by proxy. This is further complicated by the important role of the Topasses, or Black Portuguese, a mestizo group with elements of Portuguese culture, set in a localized Timorese context. Since the Topasses lived in a state of downright hostility with the White Portuguese and the Dutch for long periods of time, in effect there were three external, or semi-external, powers operating on the island. Conflicts between whites and mestizos are well known from other parts of the Portuguese colonial realm, but in the Timorese case the hostilities appear to have been more extreme. This, in turn, raises questions about how the formal and informal aspects of the Portuguese colonial complex worked in relation to each other. It also brings up issues of the workings of ethnicity and race in this period.

This brings us back to the resources available for the writing of an autonomous history of Timor. The archival material used for this study is mainly Dutch, and is found in the Nationaal Archief (Dutch National Archives) in The Hague, the Koninklijk Instituut voor Taal-, Land- and Volkenkunde (KITLV, Royal Netherlands Institute of Southeast Asian and Caribbean Studies) in Leiden, the Afdeling Oosterse Letteren (Department of Eastern Letters) of the University of Leiden, and the Arsip Nasional (ANRI, National Archive) in Jakarta. There are irregular reports on the affairs of the Dutch East India Company in the Timor region between 1613 and 1646, and regular ones after that date. In 1657, the headquarters of the VOC in this part of Indonesia were transferred from the small island of Solor to Kupang. The Dutch authorities soon came into closer contact with certain indigenous polities which sought the protection of the VOC and settled close to Kupang as subordinate allies. Due to this, certain routines of interaction were worked out in the second half of the seventeenth century. The Company regularly received information from their allies, and took pains to instruct the children of the aristocracy in Malay, the general vehicle of communication. Letters to the VOC authorities in Batavia were drawn up on a yearly basis by the allies of Timor and the neighbouring islands of Rote, Sawu and Solor. Reports written by the Dutch opperhoofd (commander, later also called resident) were likewise sent to Batavia at least once a year, with copies ending up in the Netherlands. These reports are often very verbose, encompassing several dozens of folio pages, sometimes more. The papers sent from 
Kupang to Batavia also included letters and special reports on various subjects, and occasionally minutes of council meetings and copies of Dagregisters (daily records). The latter two are particularly valuable, since they provide an idea of how the VOC operated in Timor on a day-today basis. Taken together, these sources provide valuable but piecemeal data on the history and structure of the polities that came under the orbit of Dutch influence, whilst also indicating activities throughout the rest of the island. The impressive monograph of Arend de Roever (2002) has made extensive use of the VOC material up to $1660 .{ }^{13}$ For the later periods there are a few dated, but partly still useful articles in Indologist periodicals, mostly from the nineteenth century. ${ }^{14}$

The Dutch source material is verbose but episodic in character, and is certainly not above historical criticism. When addressing the central authorities in Batavia, the opperhoofden went out of their way to justify their actions and decisions. Failures and unsatisfactory economic results were regularly blamed on the Portuguese or their indigenous allies, and occasionally, on the quality of the other staff of the trading post. We also know that several persons who were sent to Timor as opperhoofden were considered to be among the least competent of the VOC employees, and there is ample evidence of corruption. On the other hand, the organization of the VOC as a trading institution meant that there were checks on the arbitrariness of the reports that were written. The Company needed facts, not fiction, in order to take central decisions on policy and the allocation of resources.

What about the point of view of the indigenous Timorese? As a matter of fact, there is a certain output of textual documents from the VOC allies in Timor and the nearby islands of Rote, Sawu and Solor, despite these aristocrats being almost always illiterate. Letters were drawn up on a yearly basis and sent with a Company ship to the Governor General in Batavia, together with the tributes. The letters were composed with the assistance of those people linked to the VOC who could read and write, who were, in fact, sometimes ethnic Timorese. These letters display a rather formal tone and are not always very illuminating. They do, however, provide us with the Timorese version of events spoken of

\footnotetext{
13 For briefer statements of his main arguments, see De Roever 1998, 2005.

${ }_{14}$ In the first place Heijmering 1847; Van der Chijs 1872; Leupe 1877; Haga 1882a, 1882b; De Roo van Alderwerelt 1904; Fiedler 1931. More recent articles partly based on VOC materials include McWilliam 2007 and Hägerdal 2006, 2007a and 2007b.
} 
in the more verbose Dutch reports. At times they are written in a frank and critical style, thus providing an interesting corrective to colonial narratives. It is also important to remember that the Dutch were highly dependent on Timorese informers to find out what was happening on the island. Timorese voices are therefore constantly quoted in the VOC documents, albeit in a Dutch-language version.

When compared with the Dutch records, the Portuguese materials are rather different in style, more spread out and preserved in a less regular manner. For the period under scrutiny, they largely consist of reports and letters written by colonial officials in Lifau and Dili, and of missionary - in the first instance, Dominican - texts. They are less systematic and, indeed, much less preserved than the VOC records, and usually display a profound lack of interest or insight into indigenous Timorese affairs. Nevertheless, these documents are often written in a lively narrative style and contain many ethnographic details not found in the Dutch records. It is both rewarding and illuminating to compare the Portuguese and Dutch texts, since they often present different outlooks and perspectives. In this sense, the documents of each respective group can be evaluated in light of each other. Some Portuguese letters are preserved in Dutch archives; besides these, the present study has not undertaken original research in Portuguese collections. Many Portuguese records from the seventeenth and eighteenth century, perhaps the majority of them, have been published or discussed in works issued before the Indonesian invasion of East Timor in 1975. ${ }^{15}$

Apart from the output of the two institutionalized colonial powers, there is also a collection of travel writings and geographical descriptions by short-term visitors, written by travellers from France, England and further afield. In terms of the seventeenth and eighteenth century, though, these are relatively few and far between. ${ }^{16}$ Those writings that we do possess are, however, valuable, since they do not have the official character of the Dutch and Portuguese reports, but instead provide their own though certainly not unbiased - viewpoints on the island and its inhabitants. Visitors include such celebrities as Captain Bligh of the infamous Bounty mutiny, but the most valuable contribution is the long and very

\footnotetext{
15 See in the first instance the works by Castro 1867; Faria de Morais 1934, 1944; Leitão 1948, 1952; Sá 1949, 1956-58; Oliveira 1953; Matos 1974a.

${ }_{16}$ The published travel accounts are extensively discussed by Durand 2006a; this work also contains a very useful cartographic survey.
} 
involved account by the Frenchman Pelon, who stayed for several years in Company service in Kupang in the 1770s (Miller 1996; Pelon 2002).

A fourth category of sources is the body of oral Timorese narratives. As pointed out by Gregor Neonbasu (2005), the ancestors of the Timorese constitute the roots of life. In order to perform the correct rituals and preserve community, oral tradition then becomes a key link to the past. Traditions are the trunk $(u f$, in the Dawan language of West Timor) that supports the branches (tlaef) and sprouts (sufa) - metaphors for the components of society (Neonbasu 2005:ix, 70-134, 369-73). Since the first half of the nineteenth century a number of historical traditions and legends have been recorded by Dutch missionaries, visitors and officials. After 1949, certain efforts have been made by the Indonesians themselves to record the stories, though much of the oral tradition has apparently been allowed to die out, leaving very little trace; so far, there are relatively few stories available from East Timor. ${ }^{17}$ Within a Timorese local polity there were always people who were assigned the task of keeping track of origins, lists of rulers, and important stories which would anchor the cohesion of a realm. Among the Atoni ${ }^{18}$ population, who are still dominant in West Timor, there were the spokesmen for the rulers, the mafefa, who had the task of keeping track of the body of local knowledge. Among the Belu, further to the east, the corresponding figures were called makoan. The mafefa were assigned to the post due to their sharp wit, though they also tended to belong to certain lineages. Several elder persons called mafefa are still found in West Timor. However, after the end of the raja system in circa 1962, interest in their bank of knowledge has declined, and several have passed away without telling or writing down what they knew for the future generations.

Let us now consider two ways in which oral tradition can be used: firstly, the extent to which it can inform us about past events; secondly, how it can help us to understand cultural and societal structures in the long term. Compared to most parts of the world that have a strong tradi-

\footnotetext{
17 The most ambitious project to date is 'The pre-colonial history of the island of Timor together with some notes on the Makassan influence in the island' (1999), the unpublished compilation by the late Australian scholar Peter Spillett. It contains a wealth of important oral stories of the traditional kingdoms in West and East Timor; these are in English, but the word-for-word translation from local languages is rather cumbersome.

18 In this work, for the sake of convenience, I will use the word 'Atoni' rather than the more complete phrase 'Atoin Meto' or 'Atoni Pah Meto' (people of the dry land). Literally, the term 'Atoni' (Atoin) would translate as 'people'. The language of the Atoni will be referred to as Dawan; it is otherwise known as Uab Meto. The Atoni are also sometimes called Vaiquenos (Baikeno) or 'Timorese Proper'.
} 


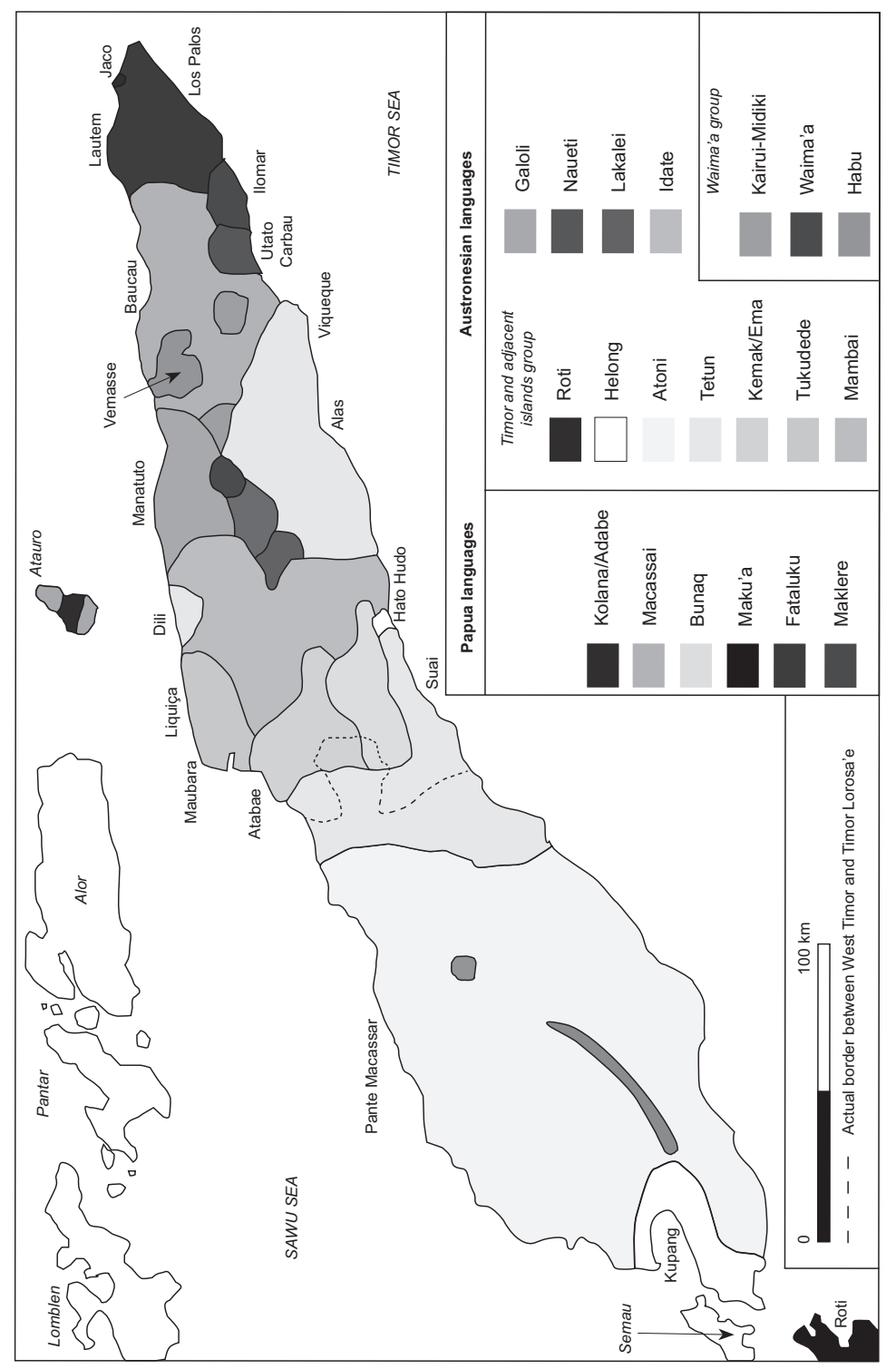

Timorese ethnolinguistic groups 
tion of oral story telling, modern scholars are in a fairly good position to evaluate the oral stories, since we possess relatively extensive European documentary records. Methods of using oral tradition have been developed in particular in the study of pre-colonial Africa, the pioneer in the field being Jan Vansina (1965). Vansina was originally very optimistic about the possibilities, and hoped to achieve a historiographical reconstruction on the basis of oral sources, achieved by comparing sources and adapting the standard means of historical criticism to the African situation. Later research has generally found these possibilities less clearcut; there are numerous traps to take into account when dealing with events beyond the scope of living memory. ${ }^{19}$ Nevertheless, in African and in some of the Asian postcolonial societies it is essential to challenge colonial narratives with indigenous ones. Here, oral tradition becomes a difficult but important corpus of sources.

The results of my own research are, unsurprisingly, ambiguous. When compared with European documents, some Timorese princely genealogies appear to be semi-reliable as far back as the second half of the seventeenth century; others are garbled, but contain fully recognizable figures from the seventeenth and eighteenth centuries. ${ }^{20}$ Yet more show details from no earlier than the nineteenth century, even though the families are known to have had a longer, more prominent history. There are also stories that can be linked to historical events dating from the mid-seventeenth century, but the content of these greatly differs between versions. In his important work on the political and societal organization of the Atoni people of West Timor (1971), H.G. Schulte Nordholt provides several examples where notable Timorese altered or reinvented historical stories, not least origin stories. It would appear that the non-literate political centre wielded a certain amount of control over the transmission of stories and information, which can also be seen by comparison with African oral tradition. ${ }^{21}$ In Timor, the ritual language used in ceremonies was a way of preserving information over numerous

\footnotetext{
19 One may compare Vansina's classic work Oral tradition (1965) with his more recent Oral tradition as history (1985), which maintains a much more careful and sceptical approach to oral materials and their methodological possibilities.

${ }_{20}$ The pedigrees of the West Timorese princely dynasties of Sonbai and Taebenu in particular appear to be fairly reliable, despite minor variations in European sources. Other pedigrees, like those of Ambeno and Amabi, mention people who are known to have been active in the seventeenth century, but supply confusing details up to the nineteenth century. For oral tradition on nearby Rote, see Fox 1971, 1979.

$21 \quad$ Finnegan 1996. Strong African kingdoms like the Ashanti maintained a biased but substantial body of orally transmitted historical knowledge in comparison with societies with weak political centres.
} 
generations, information that could not be passed on openly but only communicated in ritual contexts. In addition, the entire story was not always told through one performance; it is therefore a trying and detailed task to piece together the course of events from the various spokesmen (Neonbasu 2005:196-209). One cannot simply dismiss oral traditions when discussing Timorese history, though: they present a retrospective outlook on the historical landscape that contemporary reports are simply not able to provide. Without corroborating data they cannot be used for reconstructing events that took place more than a century before their recording, but they do provide information on how a Timorese polity preferred to remember particular events or circumstances. ${ }^{22}$ They also present Timorese views of the colonial entities, helping us understand how foreigners could, under some circumstances, be accepted as 'stranger kings', and reminding us that there were other interpretations of an event than that of peevish, impatient colonial officials.

This book does not attempt to present a general history of Timor before 1800. Although internal colonial administration and economic relations between European ports and the outside world are studied as a way of mapping patterns of policies and economic exchange in the region, they are not the focus of this study. A host of material is available in the Dutch records of the VOC period to clarify these aspects, though time and patience are required to sift through them. This work, as was previously mentioned, uses European materials to study the Timorese version of events, explaining their interaction with the Dutch and with the 'White' and 'Black' Portuguese. In particular, I will focus on the Sonbai (Sonnebay), the most prestigious dynastic group of West Timor, which has important mythical connotations. The reason for this, apart from their importance to the Timorese, is the considerable amount of information available on the Sonbai in European records and oral accounts. They tended to be involved in the dramatic crises and changes on the island from the mid-seventeenth century through to the Indonesian revolution of the twentieth century. The ever-changing fate of the Sonbai is therefore symbolic of the turbulent changes that have afflicted indigenous Timorese society since the seventeenth century.

22 Yeager and Jacobson 2002 discuss the history of the various West Timorese domains, going further than the oral tradition recorded by Parera 1994, Spillett 1999, and others. In spite of the substantial merits of Yeager and Jacobson's work, the problems of using the oral traditions as historical sources are obvious. 